\title{
Construction of a novel highly selective potentiometric perchlorate sensor based on neocuproine-Cu(II) complex formed in situ during the conditioning period
}

\author{
Ahmet Onder', \\ Cihan Topcu', \\ Fatih Coldur $^{1^{*}}$ \\ ${ }^{1}$ Department of Chemistry, \\ Faculty of Arts and Sciences, \\ Erzincan University, \\ 24100 Erzincan, Turkey
}

\begin{abstract}
A potentiometric perchlorate-selective electrode based on a phenanthroline derivative, neocuproine (2,9-dimethyl-1,10-phenanthroline), was developed. An electroactive substance, a neocuproine complex of $\mathrm{Cu}^{2+}$, providing a selective response to perchlorate was formed in situ in the electrode membrane structure during the conditioning process. Membrane optimization studies showed that the most suitable membrane composition was $1.0 \%(\mathrm{w} / \mathrm{w})$ neocuproine, $69.0 \%(\mathrm{w} / \mathrm{w})$ o-nitrophenyloctylether (o-NPOE) and $30.0 \%(\mathrm{w} / \mathrm{w})$ poly(vinyl chloride) (PVC) in terms of potentiometric performance characteristics. For the proposed electrode, the linear range, slope, detection limit, $\mathrm{pH}$ working range and response time were determined as $2.5 \times 10^{-7}-1.0 \times 10^{-1} \mathrm{M},-53.01 \mathrm{mV} /$ decade, $1.0 \times 10^{-7} \mathrm{M}, 4.0-12.5$ and $\approx 3 \mathrm{~s}$, respectively. The proposed sensor was successfully used in the determination of perchlorate contents of some perchlorate spiked tap, river and dam water samples.
\end{abstract}

Keywords: perchlorate, electrode, neocuproine, perchlorate determination, potentiometry

\section{INTRODUCTION}

Perchlorate $\left(\mathrm{ClO}_{4}^{-}\right)$is a primary constituent of solid phase rocket fuel, missiles, fireworks [1-3], explosives and air bag inflators [3], and was also found in some food products [ [4] soils [5], fertilizers [6], plants 烠] and human urines [8]. Perchlorate salts have also been used in the treatment of patients with hyperactive thyroid glands [9] and as a thyreostatic drug and growth promoter in cattle fattening [10]. The presence of a high-level perchlorate ion in the consumed products brings about great threat for human health. Because iodine and perchlorate are similar in size, the presence of perchlorate at a high level decreases the iodine uptake by the thyroid gland, which results in the deterioration of hormonal balance and physiological activities corresponding with thyroid hormones [11]. High-level

* Corresponding author. Email: fatihcoldur@hotmail.com perchlorate ion uptake by the use of a thyreostatic drug and growth promoter also causes thyroid gland tumour in the animals [12]. In the last years, day by day, perchlorate has been spread around and caused contamination in environment due to the improper storage and release of perchlorate salts. Due to the aforementioned hazardous effects of perchlorate, monitoring of perchlorate ions in environment and consumption materials has a great significance and necessitates an immediate interest.

Several different methods comprising volumetric titration [13], gravimetry [14], spectrophotometry [15], atomic absorption spectrometry [16, 17], and ion chromatography [10] have been used for the determination of perchlorate ions. However, most of these techniques have various disadvantages such as long analysis time, need for sophisticated devices, laborious pretreatment processes, high-cost measurements and need for experts. Therefore, there has been a growing need for the development of new alternative 
techniques eliminating the aforementioned disadvantages as much as possible. Ion selective electrodes (ISEs) are highly popular devices to address this need.

Potentiometric ion selective electrodes (ISEs) are frequently used routine monitoring devices for the determination of many ionic species due to a number of their advantages such as an adequate selectivity, a wide linear working range, a low limit of detection, a high accuracy, a shorter analysis time, a practical and low-cost measurement process, a simple design, a compatible use in flow-through measurements, the negligible disruptive effect on the measurement media, no prior separation from the sample matrix in most cases, a reliable determination in coloured and turbid samples [18]. In this context, earlier our research group has reported a number of cation and anion selective electrodes [19-23] and ongoing studies have been motivated on the development of novel ion selective electrodes for different species.

The most important component of an ion selective electrode responsible for a selective and sensitive response to the target ion is the membrane ingredient named as a ionophore. Until now, a number of perchlorate-selective potentiometric electrodes have been reported which were prepared based on various ionophore substances such as long chain quaternary ammonium ions [24-26], protonated dyes as bulky counter-ions [26, 27], perchlorate ion-pair complexes with cations [28], metallic organic complexes [29-34], neutral carriers [35-39], anion exchange resins [39], conducting polymers [40, 41], surfactant modified zeolits [42], chemically modified silica gel [43] and uranyl complexes [44]. Moreover, perchlorate selective electrodes reported in most of these studies lack of adequate potentiometric characteristics such as selectivity, sensitivity, response time, linear working range, life span, and detection limit. Therefore, the development of novel perchlorate selective electrodes with superior potentiometric characteristics is still of urgent need.

Neocuproine is a phenanthroline compound that is used as a chelating agent in a wide variety of applications. Moreover, a limited number of studies in which the neocuproine-metal complex is utilized as an electroactive component in the structure of an ion selective electrode have been encountered. Neocuproine-metal complexes have been shown to exhibit the anionic potentiometric response 445, 46]. Trojanowicz [45] prepared a PVC membrane nitrate selective electrode based on the bis(neocuproine)-copper(I) complex. Similarly, Stefan and co-workers [46] proposed a liquid membrane oxalate selective electrode prepared on the basis of the ion pair of oxalate with $\left[\mathrm{Fe} \text { (neocuproine) }{ }_{3}\right]^{2+}$. The underlined studies indicate that different metal complexes of neocuproine potentiometrically exhibite different selectivity properties depending on the metal type present in the structure of a complex. To the best of our knowledge, the $\mathrm{Cu}(\mathrm{II})$-neocuproine complex has not previously been used in the development of a perchlorate-selective electrode or any other ion-selective electrode. In this context, in the current paper, we investigated the potentiometric behaviours of PVC-membrane electrodes containing neocuproine- $\mathrm{Cu}(\mathrm{II})$ complexes formed in situ during the first conditioning process and demonstrated that the proposed electrode exhibited a very satisfied potentiometric response towards a perchlorate anion in terms of the potentiometric figure of merits.

\section{EXPERIMENTAL}

\section{Reagents}

Tetrahydrofuran (THF), high molecular weight poly(vinyl chloride) (PVC), $o$-nitrophenyl octyl ether (NPOE), dibutyl phthalate (DBP), dioctyl phthalate (DOP), dioctyl sebacate (DOS), potassiumtetrakis ( $p$-chlorophenyl) borate (KTp$\mathrm{ClPB})$, neocuproine and Graphite powder $(<20 \mu \mathrm{m})$ were obtained from Sigma-Aldrich.

The epoxy (TP3100) and hardener (Desmodur RFE), used in the preparation of a conductive solid contact, were purchased from Denlaks (Turkey) and Bayer AG (Germany), respectively.

All the standard and stock solutions were prepared from the analytical grade sodium salts of the respective anions.

In the preparation of aqueous solutions throughout the study, deionized water with a resistivity of $18.3 \mathrm{M} \Omega . \mathrm{cm}$ was used.

\section{Instruments}

Potentiometric measurements were carried out by using a laboratory-made high-input impedance multi-channel potentiometric measurement system controlled by a homemade software program. A saturated silver/silver chloride reference electrode (Gamry) was used throughout the potentiometric measurements. The $\mathrm{pHs}$ of the perchlorate solutions were monitored by using a model 6307 bench top $\mathrm{pH}$ meter (Jenco Ins.).

The Zeener Power II water purification system (Human Corporation) was used to obtain deionized water required throughout the study.

\section{Electrode fabrication}

For the fabrication of the electrodes, the similar procedure given in our previous work was followed [23]. At the first stage, to obtain conductive and compatible surfaces for the adherence of the selective PVC-membranes, a mixture of 50\% (w/w) graphite powder, 35\% (w/w) epoxy and 15\% $(\mathrm{w} / \mathrm{w})$ hardener was prepared by dissolving in adequate tetrahydrofurane (THF) and coated on the one open end of the shielded copper wires with a length of $5.0 \mathrm{~cm}$ and a radius of $0.5 \mathrm{~mm}$ when the appropriate viscosity was obtained. The coated wires were left to dry at ambient conditions overnight. At the second stage, the PVC membranes consisted of PVC, a plasticizer, a ionophore and in some cases ionic additives (totally $100 \mathrm{mg}$ ) at various ratios were prepared by dissolving in $1.0 \mathrm{~mL}$ THF and the resultant membrane cocktail carefully coated on the previously 
prepared conductive solid contact surfaces so as to obtain a membrane thickness of $0.2 \mathrm{~mm}$. Then the coated surfaces were left to dry in ambient conditions overnight. Prior to use, the electrodes were dipped into the $1.0 \times 10^{-2} \mathrm{M}$ $\mathrm{Cu}\left(\mathrm{NO}_{3}\right)_{2}$ solution for $24 \mathrm{~h}$. When not in use, the electrodes were stored in the laboratory conditions. Before the every measurement process, the electrodes were reconditioned about half an hour to obtain stable readings and a lower membrane resistance.

\section{Potentiometric measurements}

EMF measurements were conducted at ambient temperature with the following electrochemical cell:

$\mathrm{Ag} / \mathrm{AgCl}$ || test solution | PVC membrane | conductive solid contact | $\mathrm{Cu}$ wire.

The potentiometric data were collected when the indicator and reference electrode were immersed in $25 \mathrm{~mL}$ of the solution while stirred at a constant rate. Reference and indicator electrodes were washed with deionized water and dried with a smooth adsorbent paper between each measurement.

\section{RESULTS AND DISCUSSION}

\section{Membrane optimization}

PVC:ionophore:plasticizer:ionic additive ratios and plasticizer types are important parameters that affect the potentiometric performance properties of an ion selective electrode 47, 48. Therefore, different membrane compositions were prepared by manipulating these parameters to determine the electrode composition introducing the best potentiometric potentiometric performance characteristics (slope, detection limit, linear working range, and coefficient of determination $\left(\mathrm{R}^{2}\right)$ ).

Initially, to investigate the effect of ionophore ratio in the membrane, we prepared membranes containing a ionophore at different mass ratios. The studied membranes and their potentiometric performance characteristics were sum- marized in Table 1. When the data is examined in Table 1, it appears that the increase in the percentage of the ionophore in the membrane structure does not ensure any improvement in electrode performance, on the contrary, gives rise to more narrow linear ranges and higher detection limits. Therefore, the ionophore ratio in Membrane A was chosen as an optimum ionophore ratio and in the following membrane optimization studies, the constant ionophore ratio of $1.0 \%(\mathrm{w} / \mathrm{w})$ was used for the membrane preparations.

It should be remembered that the type and amount of a plasticizer provides a particular dielectric constant value to the membrane and influences the mobility of the ionophore and its complex [49]. Therefore, selecting a convenient plasticizer for a selective polymeric membrane is an important issue because it improves the potentiometric performance characteristics of ion-selective electrodes. At this point, the effect of plasticizer's type on the electrode performance was also investigated. The membranes containing 1.0\% (w/w) ionophore, 30.0\% (w/w) PVC and 69.0\% (w/w) plasticizer of different types were prepared. It is seen in Table 2 that the slope, linear working range and detection limit values of the PVC membrane electrode prepared with the use of o-NPOE are better than those of the membranes prepared with other plasticizers. The slope of the membrane prepared with an o-NPOE plasticizer is much better than the electrodes prepared with other plasticizers. Accordingly, it has been determined that o-NPOE is the most convenient plasticizer in terms of potentiometric performance characteristics.

The response of a PVC-membrane electrode, in most cases, depends on the concentration of lipophilic anionic salts incorporated in the membrane [50]. At this stage of the study, the effect of potassium tetrakis (4-chlorophenyl) borate (KTpClPB) inclusion into the membrane at varying ratios was investigated. For this, ionic additives at mass ratios of $0.1 \%, 0.5 \%$, and $1.0 \%$ were respectively added into the membrane previously determined as an optimum. The potentiometric performance characteristics of the membranes including $\mathrm{KTpClPB}$ at different ratios

Table 1. Effect of the ionophore ratio on the potentiometric response of the PVC membrane electrode

\begin{tabular}{c|ccccccc}
\hline Membrane & PVC:0-NP0E:ionophore \%, w/w & Slope, mv/decade & Detection limit, $\mathbf{M}$ & Linear working range, $\mathbf{M}$ & $\mathbf{R}^{\mathbf{2}}$ \\
\hline A & $30: 69: 1$ & -52.7 & $1.0 \times 10^{-7}$ & $5.0 \times 10^{-7}-1.0 \times 10^{-1}$ & 0.9998 \\
\hline B & $30: 67: 3$ & -49.6 & $5.0 \times 10^{-6}$ & $1.0 \times 10^{-6}-1.0 \times 10^{-1}$ & 0.9991 \\
\hline C & $30: 65: 5$ & -47.8 & $1.0 \times 10^{-6}$ & $5.0 \times 10^{-5}-1.0 \times 10^{-1}$ & 0.9989 \\
\hline
\end{tabular}

Table 2. Effect of the plasticizer type on the potentiometric response of the PVC membrane electrode

\begin{tabular}{cccccc}
\hline Membrane & Plasticizer & Slope, mv/decade & Detection limit, $\mathbf{M}$ & Linear working range, $\mathbf{M}$ \\
\hline A & o-NPOE & -52.7 & $1.0 \times 10^{-7}$ & $5.0 \times 10^{-7}-1.0 \times 10^{-1}$ \\
\hline D & DBF & -31.3 & $5.0 \times 10^{-6}$ & $1.0 \times 10^{-5}-1.0 \times 10^{-1}$ \\
\hline E & DOP & -18.5 & $5.0 \times 10^{-4}$ & $1.0 \times 10^{-3}-1.0 \times 10^{-1}$ \\
\hline F & DOS & -22.3 & $5.0 \times 10^{-4}$ & $1.0 \times 10^{-3}-1.0 \times 10^{-1}$ \\
\hline
\end{tabular}


were given in Table 3. As seen, the addition of KTpCIPB into the membrane resulted in serious deteriorations in the electrode behaviour. For this reason, the use of KTpClPB as a membrane ingredient has been avoided.

Membrane optimization studies indicated that the most favourable membrane composition was $1.0 \%$ ionophore, 69.0\% o-NPOE and 30.0\% PVC. In the next part of the study, the potentiometric performance characteristics of the electrode prepared in the optimum membrane composition were investigated in more detail.

\section{Potentiometric performance characteristics of the electrode}

For the determination of the potentiometric behaviour of the electrode against perchlorate ion, potentiometric measurements were taken in a series of standard solutions prepared by diluting a $1.0 \times 10^{-1} \mathrm{M}$ perchlorate stock solution with deionized water in appropriate quantities. The observed potential values depending on the varying perchlorate concentrations and the potential-concentration curve are shown as an inset in Fig. 1.

The developed perchlorate selective electrode exhibited a linear response in a concentration range of $2.5 \times 10^{-7}-$ $1.0 \times 10^{-1} \mathrm{M}$ perchlorate with an average potential change of $53.01 \pm 0.5 \mathrm{mV}$ per decade. The detection limit of the electrode was calculated from the intersection of two linear portions of the response curve as $1.0 \times 10^{-7} \mathrm{M}$ as recommended by IUPAC [51].

A vital characteristic of an ISE is its selectivity to the primary ion over interfering ions. Selectivity coefficients of the electrode, which are the indicators of the interference degree of the corresponding interferents on the potentiometric response, were calculated according to the matched potential method [52] for some commonly encountered anionic species. The calculated selectivity coefficients are given in Table 4. According to the selectivity coefficient values, it is seen that the electrode exhibited a highly selective response against the measured species.

Table 3. Effect of the ionic additive ratio on the potentiometric response of the PVC membrane electrode

\begin{tabular}{c|c|c|c|c|c}
\hline Membrane & lonic additive \%, w/w & Slope, mv/decade & Detection limit, $\mathbf{M}$ & Linear working range, $\mathbf{M}$ & $\mathbf{R}^{\mathbf{2}}$ \\
\hline $\mathrm{A}$ & 0.0 & -52.7 & $1.0 \times 10^{-7}$ & $5.0 \times 10^{-7}-1.0 \times 10^{-1}$ & 0.9998 \\
\hline $\mathrm{G}$ & 0.1 & -11.9 & $5.0 \times 10^{-7}$ & $1.0 \times 10^{-6}-1.0 \times 10^{-2}$ & 0.9947 \\
\hline H & 0.5 & -10.6 & $5.0 \times 10^{-8}$ & $1.0 \times 10^{-7}-1.0 \times 10^{-4}$ & 0.9933 \\
\hline I & 1.0 & -7.3 & $5.0 \times 10^{-8}$ & $1.0 \times 10^{-7}-1.0 \times 10^{-4}$ & 0.9921 \\
\hline
\end{tabular}

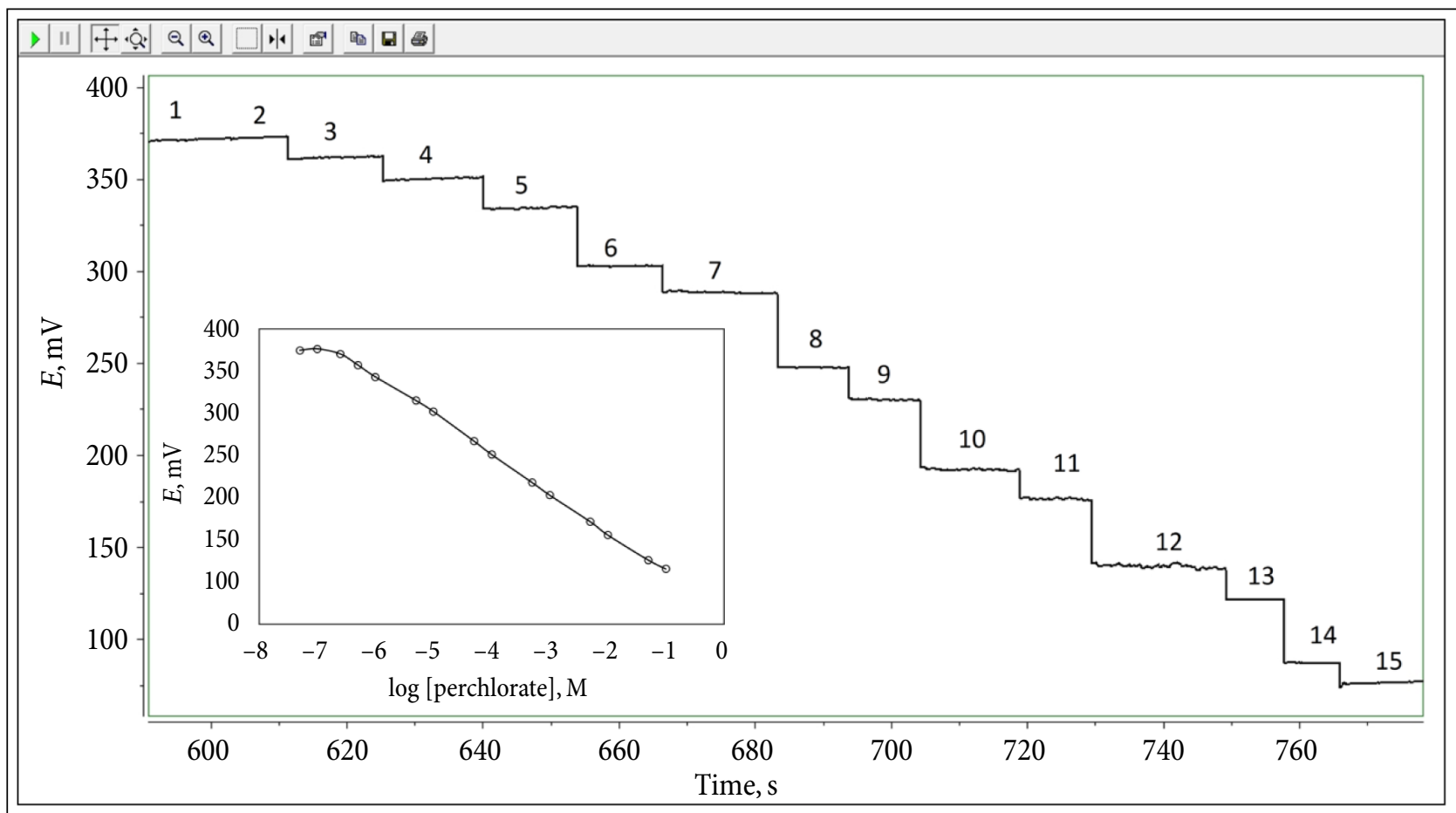

Fig. 1. Potentiometric responses of the perchlorate selective electrode in perchlorate solutions at various concentrations $\left(1: 5.0 \times 10^{-8} \mathrm{M}, 2: 1.0 \times 10^{-7} \mathrm{M}, 3: 2.5 \times 10^{-7} \mathrm{M}\right.$, $4: 5.0 \times 10^{-7} \mathrm{M}, 5: 1.0 \times 10^{-6} \mathrm{M}, 6: 5.0 \times 10^{-6} \mathrm{M}, 7: 1.0 \times 10^{-5} \mathrm{M}, 8: 5.0 \times 10^{-5} \mathrm{M}, 9: 1.0 \times 10^{-4} \mathrm{M}, 10: 5.0 \times 10^{-4} \mathrm{M}, 11: 1.0 \times 10^{-3} \mathrm{M}, 12: 5.0 \times 10^{-3} \mathrm{M}, 13: 1.0 \times 10^{-2} \mathrm{M}$, $\left.14: 5.0 \times 10^{-2} \mathrm{M}, 15: 1.0 \times 10^{-1} \mathrm{M}\right)$ 
Table 4. Selectivity coefficients (KA.B) of the PVC-membrane perchlorate-selective electrode

\begin{tabular}{|c|c|c|c|c|c|}
\hline Anion & $\log K A . B$ & Anion & $\log K A . B$ & Anion & $\log K A . B$ \\
\hline $\mathrm{SCN}^{-}$ & -1.3 & $\mathrm{PO}_{4}^{3-}$ & -2.9 & $\mathrm{CrO}_{4}{ }^{2-}$ & -3.9 \\
\hline $\mathrm{BF}_{4}^{-}$ & -1.5 & $\mathrm{NO}_{3}^{-}$ & -3.2 & $\mathrm{NO}_{2}^{-}$ & -4.2 \\
\hline $\mathrm{CO}_{3}^{2-}$ & -2.4 & $\mathrm{HPO}_{4}{ }^{2-}$ & -3.3 & $\mathrm{Cl}^{-}$ & -4.8 \\
\hline $\mathrm{Cr}_{2} \mathrm{O}_{7}{ }^{2-}$ & -2.8 & $\mathrm{Br}^{-}$ & -3.4 & $\mathrm{HSO}_{4}^{-}$ & -4.8 \\
\hline $\mathrm{HCO}_{3}{ }^{-}$ & -2.8 & $\mathrm{ClO}_{3}^{-}$ & -3.4 & $\mathrm{IO}_{3}^{-}$ & -4.8 \\
\hline $\mathrm{I}^{-}$ & -2.8 & $\mathrm{CH}_{3} \mathrm{COO}^{-}$ & -3.7 & $\mathrm{SO}_{3}^{2-}$ & -4.8 \\
\hline $\mathrm{B}_{4} \mathrm{O}_{7}^{2-}$ & -2.9 & $\mathrm{~F}^{-}$ & -3.9 & $\mathrm{SO}_{4}^{2-}$ & -4.8 \\
\hline
\end{tabular}

One characteristic of an ion selective electrode is its response time and it differs depending on the electrode type, conditioning solution, concentration range, magnitude of concentration change, interferent concentration and direction of measurement (from low to higher concentration or vice versa) [53]. In order to determine the response time of the electrode, under the condition that the solutions were stirred at a constant rate, the electrode was immersed into each standard perchlorate solution of $1.0 \times 10^{-5}, 1.0 \times 10^{-4}$, $1.0 \times 10^{-3}$ and $1.0 \times 10^{-2} \mathrm{M}$, respectively, from a low to a high concentration and vice versa. The real-time potentiometric responses (Fig. 2) were recorded depending on time and the elapsed times that the electrode responses reached to stable values were determined as $\left(\mathrm{t}_{95}\right)$ [54]. The average time that the potentials became stable was calculated and given as the response time of the electrode. The average response time of the electrode was estimated to be approximately $3 \mathrm{~s}$. As illustrated in Fig. 2 the electrode exhibited very rapid responses in all the studied perchlorate concentrations. This is the evidence that the diffusion equilibrium between an aqueous layer and an electrode membrane is very fast.

Reversibility and repeatability are also important factors for ion selective electrodes. Therefore, the repeatability of the electrode was also investigated by sequentially immersing the electrode into $1.0 \times 10^{-3}, 1.0 \times 10^{-4}$ and $1.0 \times 10^{-5} \mathrm{M}$ perchlorate solutions as shown in Fig. 3. The mean potentials and their standard deviations were calculated as $174.3 \pm 0.3$, $229.6 \pm 0.7$ and $285.8 \pm 0.8 \mathrm{mV}$ for $1.0 \times 10^{-3}, 1.0 \times 10^{-4}$

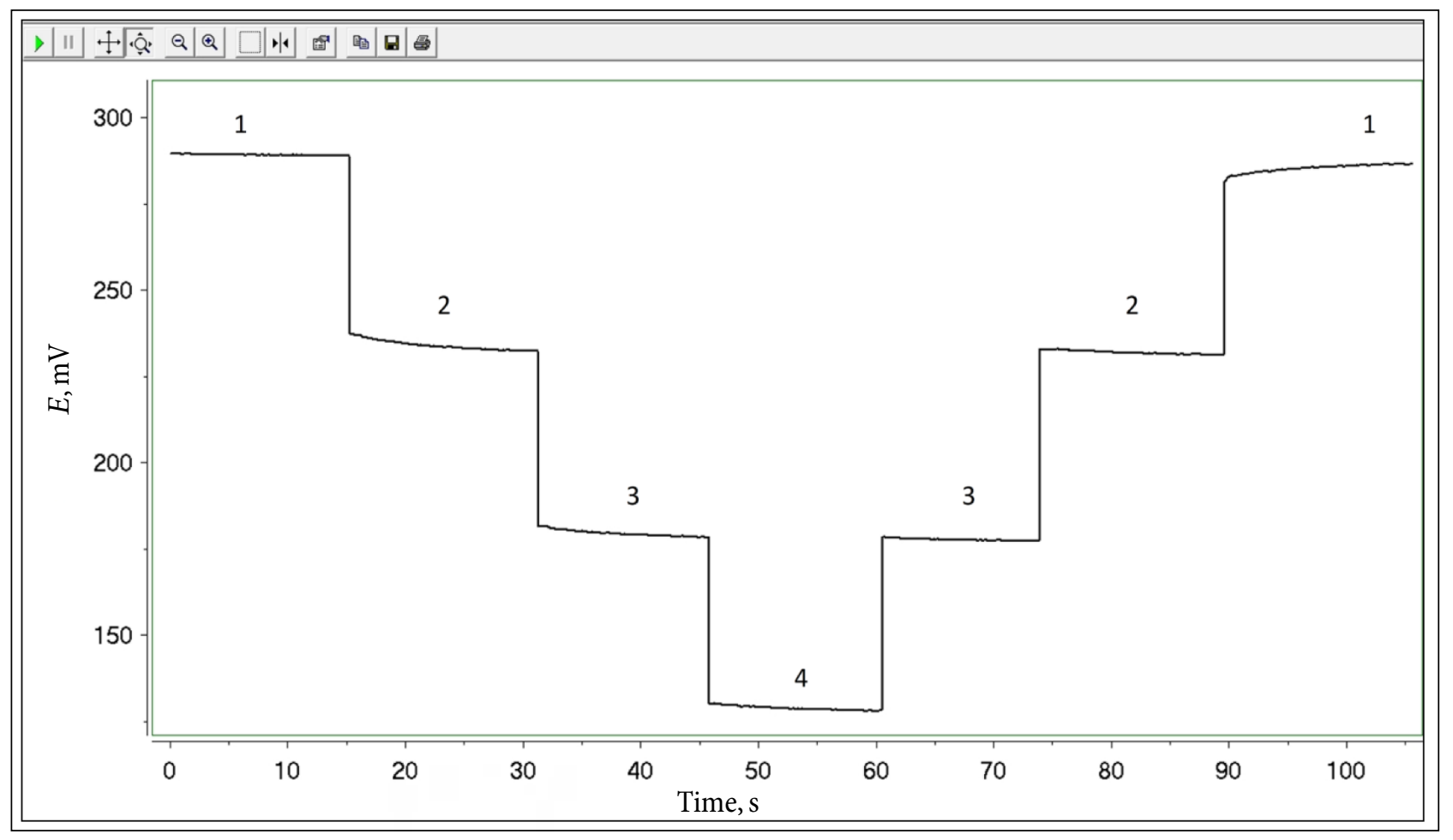

Fig. 2. Response times of the proposed perchlorate-selective electrode in perchlorate solutions at various concentrations $\left(1: 1.0 \times 10^{-5} \mathrm{M}, 2: 1.0 \times 10^{-4} \mathrm{M}\right.$, 3: $1.0 \times 10^{-3} \mathrm{M}, 4: 1.0 \times 10^{-2} \mathrm{M}$ ) 


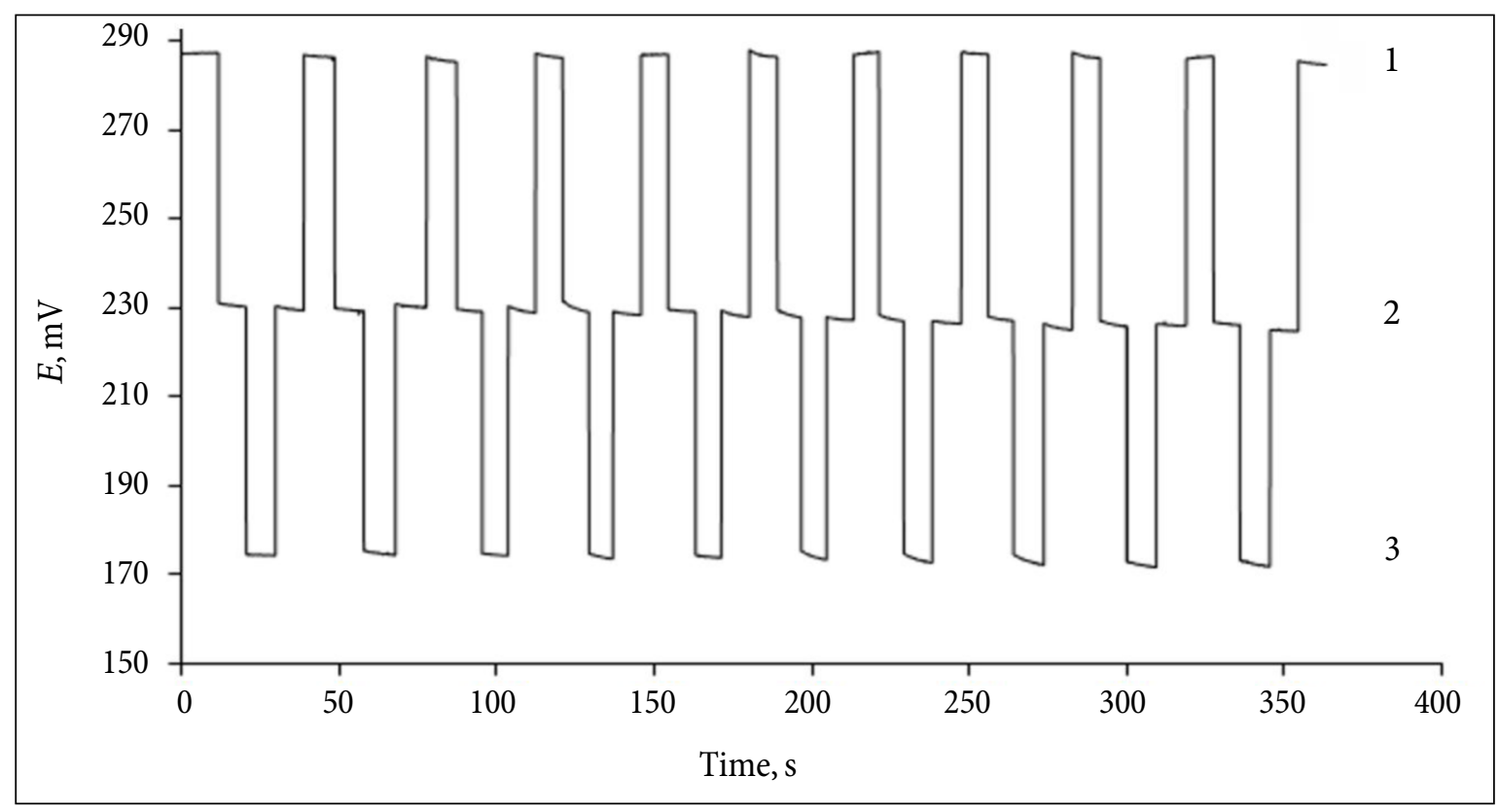

Fig. 3. Repeatability and reversibility of the perchlorate-selective electrode in perchlorate solutions at various concentrations $\left(1: 1.0 \times 10^{-5}, 2: 1.0 \times 10^{-4}\right.$ and $3: 1.0 \times 10^{-3} \mathrm{M}$ perchlorate solutions)

and $1.0 \times 10^{-5} \mathrm{M}$ perchlorate solutions, respectively. The obtained results indicate that the proposed electrode exhibits highly reversible and repeatable potentiometric responses in the studied concentration range.

Because it is possible to use an ISE in a wide variety of samples at different $\mathrm{pHs}$, it is needed to have information about the $\mathrm{pH}$ working range in which the electrode well func- tioned. The influence of the $\mathrm{pH}$ on the electrode response was investigated by using the $1.0 \times 10^{-3} \mathrm{M}$ and $1.0 \times 10^{-4} \mathrm{M}$ aqueous perchlorate solutions at different $\mathrm{pHs}$. The $\mathrm{pH}$ of the solution was adjusted by adding the adequate amounts of $\mathrm{HCl}$ and $\mathrm{NaOH}$ solutions. The potential data of the electrochemical cell were collected depending on the $\mathrm{pH}$ change of the solutions and the plot shown in Fig. 4 was constructed.

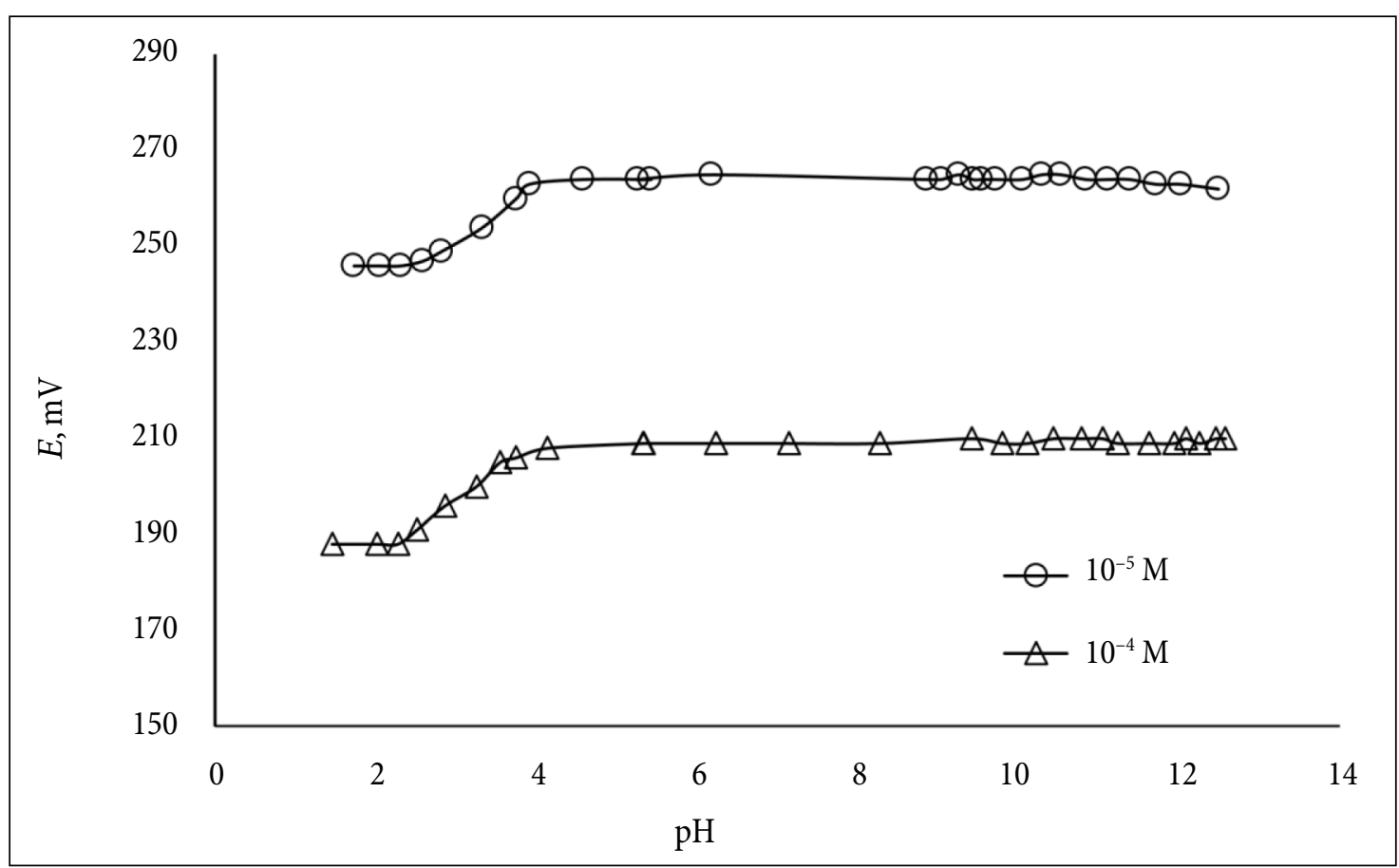

Fig. 4. pH dependence of the electrode response in the fixed perchlorate concentrations as a background 
As seen, the potentiometric response of the electrode at $\mathrm{pH}=4.0-12.5$ range is not significantly affected by the $\mathrm{pH}$ change. However, at lower $\mathrm{pH}$ values $(<4.0)$, the potential values begin to decrease rapidly. This tendency is presumably due to the increasing $\mathrm{Cl}^{-}$concentrations in the environment with the addition of $\mathrm{HCl}$ used for the $\mathrm{pH}$ adjustment. At high $\mathrm{pH}$ values $(>10.5)$ a slight decrease in the potential values is observed. This can be explained by the increasing concentration of $\mathrm{OH}^{-}$ion in the medium with increasing $\mathrm{pH}$. However, this decline is not a notable one.

It is desired that an ion-selective electrode should be used continuously for a long period of time without any significant change in its potentiometric behaviour. However, the lifetime of each electrode varies depending on the stability and type of the selective membrane, frequency of use and the storage conditions. In PVC membrane electrodes, especially, the leakage of the electroactive component into the measurement media and swelling of the membrane in water in the long run cause loss of performance in potentiometric properties. In the current study, the lifetime of the electrode was investigated by monitoring the change in the slope of the calibration curve depending on time. Figure 5 illustrates the slope values of the calibration plots derived from the perchlorate solutions in a concentration range of $1.0 \times 10^{-5}-1.0 \times 10^{-1} \mathrm{M}$ depending on time. The figure shows that the slope of the calibration curve begins to decrease significantly after a time period of 60 days. As a result, the lifetime of the electrode can be accepted as about two months.

\section{Comparison of the electrode properties with other} studies

Some potentiometric performance parameters of the proposed electrode and some selected perchlorate selective electrodes available in the literature were given comparatively in Table 5. Most of the potentiometric performance characteristics of the developed electrode were found to be better than some of the existing perchlorate-selective electrodes in the literature.

\section{Analytical applications}

The analytical application of the electrode was achieved by making determinations in different water samples such as river, dam and municipal water samples. Initially, perchlorate determinations were tried to be performed by a direct calibration method in order to have an idea about whether the perchlorate contents of these samples could be determined by the proposed electrode. However, it was observed that the measured potential values corresponding to the concentration values were quite below the previously calculated detection limits in aqueous samples. For this reason, different known amounts of perchlorate were added to these samples to obtain concentrations falling within the linear working range and perchlorate determinations were carried out by using both direct calibration and standard addition methods.

The analysis results obtained by using both methods are summarized in Table 6. Taking a brief look at the results, it can be seen that the recovery values obtained by using the standard addition method alter between $104-118 \%$,

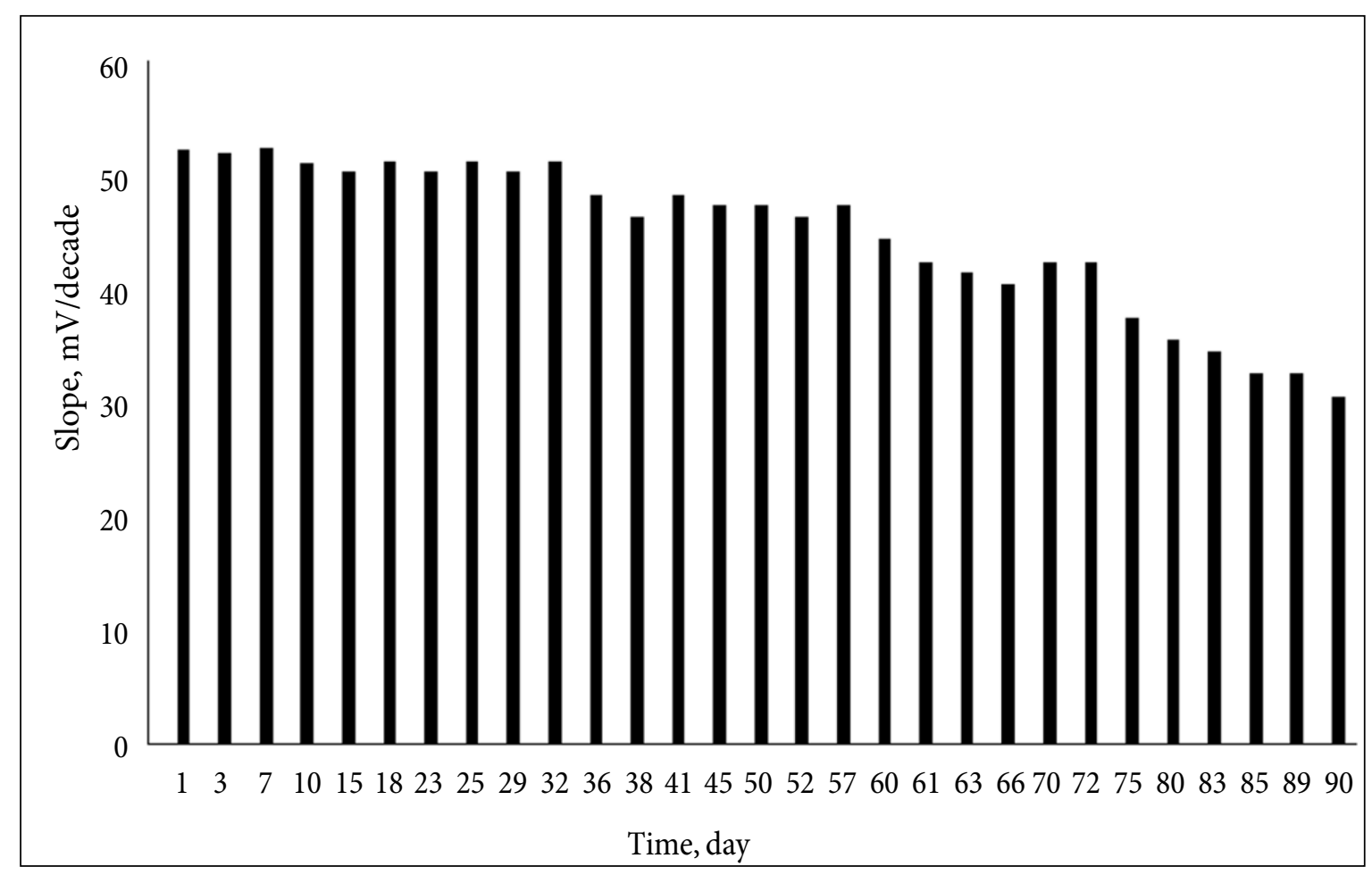

Fig. 5. Investigation of the lifetime of the electrode depending on the changes in the slope by time 
Table 5. Comparison of some potentiometric characteristics of the proposed perchlorate selective electrode with those of other perchlorate-selective electrodes developed in literature

\begin{tabular}{|c|c|c|c|c|c|c|c|}
\hline Ref. & $\begin{array}{c}\text { Slope, } \\
\mathrm{mV} / \text { decade }\end{array}$ & $\begin{array}{c}\text { Linear working range, } \\
\text { M }\end{array}$ & $\begin{array}{c}\text { Detection limit, } \\
\text { M }\end{array}$ & $\begin{array}{l}\text { pH work- } \\
\text { ing range }\end{array}$ & $\begin{array}{l}\text { Response } \\
\text { time, } s\end{array}$ & $\begin{array}{l}\text { Lifetime, } \\
\text { day }\end{array}$ & Selectivity $\left(\log K_{A, B}\right)$ \\
\hline [11] & -60.3 & $1.0 \times 10^{-1}-8.0 \times 10^{-7}$ & $5.6 \times 10^{-7}$ & $2.0-9.0$ & 5 & 60 & $\begin{array}{c}\mathrm{SCN}^{-}=-0.73, \mathrm{CO}_{3}{ }^{2-}=-2.54 \\
\mathrm{I}^{-}=-1.35, \mathrm{Br}^{-}=-2.13 \\
\mathrm{Cl}^{-}=-3.12, \mathrm{NO}_{3}^{-}=-1.7 \\
\mathrm{IO}_{3}^{2-}=-2.31, \mathrm{~F}^{-}=-2.62 \\
\mathrm{SO}_{3}^{2-}=-2.19, \mathrm{ClO}_{3}^{-}=-2.12 \\
\mathrm{SO}_{4}{ }^{2-}=-2.74\end{array}$ \\
\hline [38] & -57.0 & $1.0 \times 10^{-1}-7.0 \times 10^{-4}$ & $5 \times 10^{-5}$ & $5.0-13.0$ & 5 & 25 & $\begin{array}{c}\mathrm{SCN}^{-}=-1.74, \mathrm{CO}_{3}{ }^{2-}=-1.78 \\
\mathrm{Br}^{-}=-2.64, \mathrm{Cl}^{-}=-3.01 \\
\mathrm{I}^{-}=-2.10, \mathrm{SO}_{4}^{2-}=-3.73 \\
\mathrm{NO}_{3}^{-}=-2.44, \mathrm{C}_{2} \mathrm{O}_{4}^{2-}=-3.79 \\
\mathrm{PO}_{4}^{3-}=-3.16, \mathrm{CH}_{3} \mathrm{COO}^{-}=-2.68\end{array}$ \\
\hline [55] & - & $1.6 \times 10^{-1}-8.0 \times 10^{-6}$ & $5.0 \times 10^{-6}$ & $4.0-10.0$ & - & - & $\begin{array}{c}\mathrm{SCN}^{-}=-2.0, \mathrm{I}^{-}=-1.5, \mathrm{Br}^{-}=-3.0, \\
\mathrm{Cl}^{-}=-3.7, \mathrm{NO}_{2}^{-}=-3.3, \\
\mathrm{SO}_{4}^{2-}=-4.2, \mathrm{NO}_{3}^{--}=-3.8, \\
\mathrm{~F}^{-}=-4.1, \mathrm{CN}^{-}=-2.9, \\
\mathrm{CH}_{3} \mathrm{COO}^{-}=-2.8\end{array}$ \\
\hline [56] & -55.0 & $1.0 \times 10^{-1}-7.0 \times 10^{-7}$ & $3 \times 10^{-7}$ & $4.0-9.0$ & 15 & 90 & $\begin{array}{c}\mathrm{SCN}^{-}=-2.0, \mathrm{CO}_{3}^{2-}=-5.4 \\
\mathrm{I}^{-}=-2.7, \mathrm{Br}^{-}=-2.8, \mathrm{Cl}^{-}=-4.1 \\
\mathrm{SO}_{3}^{2-}=-4.8, \mathrm{NO}_{2}^{--}=-4.5 \\
\mathrm{~F}^{-}=-4.0, \mathrm{CN}^{-}=-2.9 \\
\mathrm{CH}_{3} \mathrm{COO}^{-}=-2.8, \mathrm{PO}_{4}^{3-}=-3.1 \\
\mathrm{SO}_{4}^{2-}=-4.3 \mathrm{SCN}^{-}=-1.3\end{array}$ \\
\hline $\begin{array}{l}\text { Present } \\
\text { work }\end{array}$ & -53.0 & $1.0 \times 10^{-1}-2.5 \times 10^{-7}$ & $1.0 \times 10^{-7}$ & $4.0-12.5$ & 3 & 75 & $\begin{array}{c}\mathrm{CO}_{3}{ }^{2-}=-2.4, \mathrm{I}^{-}=-2.8, \mathrm{Br}^{-}=-3.4, \\
\mathrm{Cl}^{-}=-4.8, \mathrm{NO}_{3}^{-}=-3.2, \\
\mathrm{IO}_{3}{ }^{2-}=-4.8, \mathrm{~F}^{-}=-3.9, \\
\mathrm{SO}_{3}^{2-}=-4.8, \mathrm{ClO}_{3}^{--}=-3.4, \\
\mathrm{SO}_{4}{ }^{2-}=-4.8, \mathrm{CH}_{3} \mathrm{COO}^{-}=-3.7\end{array}$ \\
\hline
\end{tabular}

Table 6 . Analytical application of the perchlorate selective electrode in perchlorate-spiked real water samples

\begin{tabular}{|c|c|c|c|c|c|c|c|}
\hline & \multirow{2}{*}{ [Perchlorate], M } & \multicolumn{3}{|c|}{ Direct calibration } & \multicolumn{3}{|c|}{ Standard addition } \\
\hline & & Found \pm std $^{\mathrm{a}}, \mathbf{M}$ & Recovery, \% & $t$ value $^{b}$ & Found \pm std ${ }^{\mathrm{a}}, \mathrm{M}$ & Recovery, \% & $t$ value $^{\mathrm{b}}$ \\
\hline \multirow{3}{*}{ Municipal water } & $5.0 \times 10^{-6}$ & $7.1 \pm 0.5 \times 10^{-6}$ & 142 & 7.27 & $5.7 \pm 0.3 \times 10^{-6}$ & 114 & 4.04 \\
\hline & $1.0 \times 10^{-5}$ & $1.3 \pm 0.2 \times 10^{-5}$ & 130 & 2.60 & $1.1 \pm 0.1 \times 10^{-5}$ & 110 & 1.73 \\
\hline & $5.0 \times 10^{-5}$ & $6.5 \pm 0.3 \times 10^{-5}$ & 130 & 8.66 & $5.3 \pm 0.2 \times 10^{-5}$ & 106 & 2.59 \\
\hline \multirow{3}{*}{ River water } & $5.0 \times 10^{-6}$ & $7.1 \pm 0.4 \times 10^{-6}$ & 142 & 9.09 & $5.9 \pm 0.4 \times 10^{-6}$ & 118 & 3.90 \\
\hline & $1.0 \times 10^{-5}$ & $1.2 \pm 0.1 \times 10^{-5}$ & 120 & 3.46 & $1.1 \pm 0.1 \times 10^{-5}$ & 110 & 1.73 \\
\hline & $5.0 \times 10^{-5}$ & $6.3 \pm 0.2 \times 10^{-5}$ & 126 & 11.25 & $5.4 \pm 0.3 \times 10^{-5}$ & 108 & 2.31 \\
\hline \multirow{3}{*}{ Dam water } & $5.0 \times 10^{-6}$ & $6.0 \pm 0.3 \times 10^{-6}$ & 120 & 5.77 & $5.2 \pm 0.2 \times 10^{-6}$ & 104 & 1.73 \\
\hline & $1.0 \times 10^{-5}$ & $1.3 \pm 0.3 \times 10^{-5}$ & 130 & 1.73 & $1.1 \pm 0.2 \times 10^{-5}$ & 110 & 0.87 \\
\hline & $5.0 \times 10^{-5}$ & $6.3 \pm 0.4 \times 10^{-5}$ & 126 & 5.63 & $5.2 \pm 0.3 \times 10^{-5}$ & 104 & 1.15 \\
\hline
\end{tabular}

${ }^{\text {a }}$ Number of measurements: $N=3$.

${ }^{\mathrm{b}}$ Two-sided $t_{\text {critic }}=3.40$ for $N=3$ at $95 \%$ confidence level. 
while the recovery values are between $120-142 \%$ with the use of the direct calibration method. In addition, twosided t test was applied for the comparison of the obtained mean values with the actual values at the $95 \%$ confidence level. It is clearly seen that a vast majority of the $t$ values obtained in the direct calibration method are greater than the $t_{\text {critical }}(3.40)$ value at the $95 \%$ confidence level. These statistical results refer to that the measured values deviate significantly from the actual value at the 95\% confidence level. On the other hand, all the $t$ values (except for the dam and municipal water samples contained $5.0 \times 10^{-6} \mathrm{M}$ perchlorate) obtained by using the standard addition method are lower than the $t_{\text {critical }}$ value. These results indicate that the obtained results are not statistically different from the actual values.

\section{CONCLUSIONS}

The findings obtained in this paper have shown that the potentiometric PVC membrane electrode prepared based on the $\mathrm{Cu}^{2+}$-neocuproine complex which is formed in situ during the conditioning period of the membrane exhibited a fairly good affinity to perchlorate ions compared to the most commonly encountered interferents. The electrode showed a low detection limit, a wide linear working range, a short response time, an appropriate selectivity, a long-term stability and a wide $\mathrm{pH}$ range. These analytical characteristics of the developed electrode are comparable to those of other perchlorate-selective electrodes reported in the literature and make it a useful analytical tool in the determination of a perchlorate alternative to other sophisticated and expensive detection methods. The ease of preparation and the low-cost of the proposed electrode are its other major advantages. Besides, with a fairly short response time, the electrode is appropriate for use as a detector combined with automated analysis systems such as flow injection analysis and ion chromatography.

Received 4 October 2017 Accepted 27 November 2017

\section{References}

1. E. T. Urbansky, Biochem. J., 2, 81 (1998).

2. E. T. Urbansky, M. R. Schock, J. Environ. Manage., 56, 79 (1999).

3. M. L. Magnuson, E. T. Urbansky, C. A. Kelty, Anal. Chem., 72, 25 (2000).

4. A. J. Krynitsky, R. A. Niemann, D. A. Nortrup, Anal. Chem., 76, 5518 (2004).

5. P. Winkler, M. Minteer, J. Willey, Anal. Chem., 76, 469 (2004).

6. S. Susarla, T. W. Collette, A. W. Garrison, S. C. McCutcheon, Environ. Sci. Technol., 33, 3469 (1999).

7. J. J. Ellington, N. L. Wolfe, A. W. Garrison, J. J. Evans, J. K. Avants, Q. Teng, Environ. Sci. Technol., 35, 3213 (2001).
8. L. Valentin-Blasini, J. P. Mauldin, D. Maple, B. C. Blount, Anal. Chem., 77, 2475 (2005).

9. B. E. Logan, Bioremediation J., 2, 69 (1998).

10. P. Batjoens, H. F. De Brabander, L. T'Kindt, Anal. Chim. Acta, 275, 335 (1993).

11. B. Rezaei, S. Meghdadi, S. Bagherpour, J. Hazard. Mater., 161, 641 (2009).

12. D. Ting, R. A. Howd, A. M. Fan, G. V. Alexeeff, Environ. Health Perspect., 114, 881 (2006).

13. R. J. Baczuk, W. T. Bolleter, Anal. Chem., 39, 93 (1967).

14. A. I. Vogel, Text Book of Quantitative Inorganic Analysis, 4th edn., Longman, London (1978).

15. J. A. Weiss, J. B. Stanbury, Anal. Chem., 44, 619 (1972).

16. M. Gallego, M. Valcarcel, Anal. Chim. Acta, 169, 161 (1985).

17. S. Chattaraj, K. De, A. K. Das, Microchim. Acta, 106, 183 (1992).

18. G. S. Kanberoglu, F. Coldur, C. Topcu, O. Cubuk, IEEE Sens. J., 15, 6199 (2015).

19. C. Topcu, Talanta, 161, 623 (2016).

20. C. Topcu, F. Coldur, M. Andac, et al., J. Chem. Soc. Pak., 38(5), 882 (2016).

21. O. Cubuk, B. Caglar, C. Topcu, et al., Appl. Surf. Sci., 338, 99 (2015).

22. C. Topcu, F. Coldur, M. Andac, I. Isildak, N. Senyuz, H. Bati, Current Anal. Chem., 7, 136 (2011).

23. C. Topcu, S. Caglar, B. Caglar, et al., Adv. Nat. Sci.: Nanosci. Nanotechnol., 7, 035012 (2016).

24. C. J. Coetzee, H. Freiser, Anal. Chem., 41, 1128 (1969).

25. S. Back, Anal. Chem., 44, 1696 (1972).

26. A. G. Fogg, A. S. Pathan, D. T. Burns, Anal. Chim. Acta, 73, 220 (1974).

27. E. Hopirtean, E. Stefaniga, Rev. Roum. Chim., 23, 137 (1978).

28. S. H. Almeer, I. A. Zogby, S. S. Hassan, Talanta, 129, 191 (2014).

29. C. Sanchez-Pedreno, J. A. Ortuno, J. Hernandez, Anal. Chim. Acta, 415, 159 (2000).

30. M. R. Ganjali, M. Yousefi, T. Poursaberi, L. Naji, M. SalavatiNiasari, M. Shamsipur, Electroanal., 18, 1476 (2003).

31. M. R. Ganjali, P. Norouzi, F. Faridbod, M. Yousefi, L. Naji, M. Salavati-Niasari, Sens. Actuators, B, 120, 494 (2007).

32. A. Shokrollahi, M. Ghaedi, H. R. Rajabi, A. H. Kianfar, Chin. J. Chem., 27, 258 (2009).

33. A. Soleymanpour, B. Garaili, S. M. Nabavizadeh, Monatsh. Chem., 139, 1439 (2008).

34. F. Gholamian, M. A. Sheikh-Mohseni, M. Salavati-Niasari, Mat. Sci. Eng. C, 31, 1688 (2011).

35. J. Lizondo-Sabater, M. J. Segui, J. M. Lloris et al., Sens. Actuators, B, 101(1-2), 20 (2004).

36. A. A. Memon, A. R. Solangi, S. Memon, A. A. Bhatti, A. A. Bhatti, Polycycl. Aromat. Compd., 36(2), 106 (2016).

37. A. K. Jain, J. Raisoni, R. Kumar, S. Jain, Int. J. Environ. Anal. Chem., 87(8), 553 (2007).

38. M. J. Segui, J. Lizondo-Sabater, R. Martinez-Manez, et al., Sensors, 6(5), 480 (2006).

39. K. Y. Yamamoto, S. M. Mitsuda, N. O. Ohtake, N. M. Murashige, S. O. Ohmuro, A. Yuchi, Anal. Sci., 33, 159 (2017). 
40. T. A. Bendikov, T. C. Harmon, Anal. Chim. Acta, 551(1-2), 30 (2005).

41. A. Hulanicki, A. Michalska, A. Lewenstam, Electroanalysis, 6(7), 604 (1994).

42. A. Nezamzadeh-Ejhieh, A. Badri, J. Electroanal. Chem., 660(1), 71 (2011).

43. J. R. Fernandes, L. T. Kubota, Y. Gushikem, G. de Oliveira Neto, Anal. Lett., 26(12), 2555 (1993).

44. M. M. Ardakani, M. Jalayer, H. Naeimi, H. R. Zare, L. Moradi, Anal. Bioanal. Chem., 381(6), 1186 (2005).

45. M. Trojanowicz, Fresenius Z. Anal. Chem., 297, 414 (1979).

46. R. I. Stefan, I. Draghici, G. E. Baiulescu, Sens. Actuators, B, 65(1), 250 (2000).

47. M. Shamsipur, S. Y. Kazemi, K. Niknam, H. Sharghi, Bull. Korean Chem. Soc., 23, 53 (2002).

48. E. Bakker, P. Buhlmann, E. Bakker, Chem. Rev., 97, 3083 (1997).

49. P. M. Gehrig, W. E. Morf, M. Welti, E. Pretsch, W. Simon, Helv. Chim. Acta., 73, 203 (1990).

50. R. Eugster, P. M. Gehring, W. E. Morf, U. E. Spichiger, W. Simon, Anal. Chem., 63, 2285 (1991).

51. E. Lindner, Y. Umezawa, Pure Appl. Chem., 80(1), 85 (2008).

52. Y. Umezawa, P. Buhlmann, K. Umezawa, K. Tohda, S. Amemiya, Pure Appl. Chem., 72(10), 1851 (2000).
53. C. Macca, Anal. Chim. Acta, 512(2), 183 (2004).

54. R. P. Buck, E. Lindner, Pure Appl. Chem., 66, 2527 (1994).

55. M. Shamsipur, A. Soleymanpour, M. Akhond, H. Sharghi, A. R. Hasaninejad, Sens. Actuators, B, 89, 9 (2003).

56. M. M. Ardakani, R. Mazidi, M. H. Mashhadizadeh, H. Naeimi, K. Rabiei, Iran. J. Chem. Chem. Eng., 29(3), 123 (2010).

Ahmet Onder, Cihan Topcu, Fatih Coldur

NAUJO LABAI ATRANKAUS POTENCIOMETRINIO

PERCHLORATO JUTIKLIO KŪRIMAS NAUDOJANT

NEOKUPROINO-Cu(II) KOMPLEKSĄ, SUSIDARANTI

KONDICIONAVIMO METU

Santrauka

Panaudojus fenantrolino darinį 2,9-dimetil-1,10-fenantroliną sukurtas potenciometrinis atrankus perchloratui elektrodas. Elektroaktyvi medžiaga - neokuproino kompleksas su vario (II) jonais - buvo sudaroma elektrodo membranoje tiesiogiai kondicionavimo metu. Optimizuoti komponentų santykiai, nustatytos ir aprašytos elektrodo analitinès charakteristikos. 